\title{
Foreign Body Larynx in ORL Department of University Hospital-Yalgado Ouedraogo
}

\author{
Yvette Marie Chantal Gyébré ${ }^{*}$, Noé Zaghré2, Aboubacar Gouéta1, Maimouna Ouattara1, \\ Kampadilemba Ouoba ${ }^{1}$ \\ ${ }^{1}$ Service d'ORL et de CC-F, CHU-YO, Ouagadougou, Burkina Faso \\ ${ }^{2}$ Service d'ORL et de CC-F, Blaise Compaoré, Ouagadougou, Burkina Faso \\ Email: "ycgyebre@gmail.com, zagnoe@yahoo.fr, egoueta@yahoo.com, ouattmouna@yahoo.fr, \\ ouobakpd@yahoo.fr
}

Received 14 March 2016; accepted 14 May 2016; published 17 May 2016

Copyright (C) 2016 by authors and Scientific Research Publishing Inc.

This work is licensed under the Creative Commons Attribution International License (CC BY).

http://creativecommons.org/licenses/by/4.0/

(c) (i) Open Access

\begin{abstract}
Introduction: Foreign bodies of the larynx are serious. They can be immediately life-threatening. The aim of this study was to report the epidemiological and clinical features that characterize this affection. Material and method: We retrospectively reviewed the clinical records of patients admitted to foreign bodies of the lower airways in the Otorhinolaryngology (ORL) department of the University Hospital-Yalgado Ouedraogo (UH-YO) from 2008 to 2012. Results: Seventeen (17) foreign body records were compiled on a group of 76 foreign bodies of the lower airways. The average age was 5 years. Patients ranged in age from 6 months to 35 years with a sex ratio of 1.4. The call signs were the penetration syndrome that was found in 4 cases $(23.5 \%)$, laryngeal dyspnea was found in 8 cases (47.05\%) with stage II to III and dysphonia 10 cases $(58.8 \%)$. The extraction was done endoscopically in all patients, and a tracheostomy was made in 2 cases $(11.7 \%)$. A death was noted in 1 case $(5.9 \%)$. Conclusion: The laryngeal foreign bodies are common and maintain their classical gravity. It should be thought about in front of any dyspnea associated with dysphonia in children previously healthy. The prevention is the key weapon in our context.
\end{abstract}

\section{Keywords}

Larynx, Foreign Body, Endoscopy

\section{Introduction}

The emergence of a foreign body in the lower airways carries out an emergency ENT. It is often a relatively

${ }^{*}$ Corresponding author.

How to cite this paper: Gyébré, Y.M.C., Zaghré, N., Gouéta, A., Ouattara, M. and Ouoba, K. (2016) Foreign Body Larynx in ORL Department of University Hospital-Yalgado Ouedraogo. International Journal of Otolaryngology and Head \& Neck Surgery, 5, 129-133. http://dx.doi.org/10.4236/ijohns.2016.53022 
common accident and is the appanage of the child from 1 to 4 years [1]. If the bronchial localization is most common and relatively tolerated, the laryngeal location is severe and can be immediately life-threatening.

The inhalation of a foreign body has experienced in recent decades a remarkable improvement in prognosis [2]. This improvement is linked to progress in the field of endoscopic equipment and that of the anesthetic approach. The prognosis remains however encumbered with a mortality and a morbidity not insignificant. In underdeveloped countries like ours, the difficulties in the management of this affection are numerous. The population of Burkina Faso is characterized by its sharp youth (the less than under 15 years accounted for $47 \%$ of the population) [3] and its rate of infant mortality which is situated among the highest in the world (78.3 \%) [3]-[5]. This makes necessary and appropriate every approach to improve the efficient and optimal management of childhood diseases. It is in this light that we are interested at the issue of foreign body in the lower respiratory tract more precisely of the larynx.

Numerous studies have been done on the subject and focused on its clinical aspects and their seriousness [2]. In Burkina, Ouoba's works in 2002 [1] have already allowed a glimpse of this pathology. In order to make our contribution in improving the management of this affection, we initiated the present study whose purpose was to identify the epidemiological, clinical and therapeutic features characterizing the irruption of a foreign body in the airways lower.

The aim of this study was to identify epidemiological, clinical and therapeutic features that characterize the foreign bodies of the larynx in our context in order to make the inventory of fixtures.

\section{Material and Method}

This is a retrospective study over 5 years from 2008 to 2012 and concerning 17 patients files admitted to the ENT department and Facial Neck Surgery of University Hospital Yalgado Ouedraogo. The data were collected from clinical records and the register of the operating room. The parameters studied were age, sex, clinical and laboratory signs (radio-endoscopy) and treatment.

Every patient presenting a foreign body in the larynx registered in ENT department during the study period was included in the study.

We excluded the patients who had no exploitable medical files and who were absent from the hospitalization register.

The data were analyzed using Epi Info 3.5.1 in its French version. The ethical considerations have been approved by the patient and ethics and compliance committee.

\section{Results}

In 5 years, we have collected 17 patients with laryngeal foreign body on a group of 76 foreign bodies lower respiratory or 3 cases per year and $22.4 \%$ of foreign bodies of the lower airways. The average age was 05 years with extremes 6 months and 35 years. The sex ratio was 1.4. The admission time was particularly long, $70 \%$ of children received beyond 24 hours.

At the clinical level, the laryngeal dyspnea was found in 8 cases (47.05\%) and the dysphonia in 10 cases (58.8\%). The penetration syndrome was found in 4 cases (23.5\%).The clinical examination was normal in 13 cases (76.4\%). The clinical signs are presented in Table 1.

The radiological examination was normal in 15 cases (88.2\%). A radiopaque foreign body was highlighted in 2 cases $(11.8 \%)$.

The foreign bodies were organic in $47.05 \%$ of cases and non-organic in $41.2 \%$ of cases.

The details of the nature of the foreign bodies are given in Table 2.

The groundnut (seed and pod) was the most organic foreign body find with 3 cases (37.5\%), followed by maize grain with 2 cases (25\%). The stones occupied the 1st place inorganic foreign bodies with 2 cases.

Therapeutically, the direct laryngoscopy Mac Intosh often associated with laryngeal tracheobronchoscopy practiced for foreign body extraction in all patients. The foreign bodies were subglottic in most cases (12 cases). They were glottal in 3 cases and glottal above in 2 cases. The endoscopy was repeated in 6 cases (35.3\%). The tracheostomy was done in 2 cases (11.7\%). One is before extraction and the other is after.

The complications were constituted by an edema subglottic in 1 case, a severe respiratory distress 1 case, a laryngeal spasm 1 case. The evolution was marked by a death in 1 case (5.9\%). 
Table 1. Clinical signs according to the patients.

\begin{tabular}{ccc}
\hline Clinical signs & Number & Percentage \\
\hline Dysphonia & 10 & 58.8 \\
Laryngeal dyspnea & 08 & 47.05 \\
Penetration syndrome & 04 & 23.5 \\
Normal examination & 09 & 52.9 \\
\hline
\end{tabular}

\begin{tabular}{|ccc|}
\hline Table 2. Nature of foreign body. & & \\
\hline Nature of the foreign body & Number & Percentage \\
\hline Organic & & \\
\hline Groundnut & 04 & 23.5 \\
Maize grains & 03 & 17.6 \\
Bean grain & 01 & 5.9 \\
Baobab grain & 01 & 5.9 \\
Bone & 01 & 5.9 \\
\hline Anorganic & & \\
\hline Pebbles & 03 & 17.6 \\
Plastic objects & 02 & 11.8 \\
Beads & 01 & 5.9 \\
Earrings & 01 & 5.9 \\
\hline
\end{tabular}

\section{Discussion}

The retrospective nature of our study was source of some limitations: some clinical records have not been found, others were incompleted, some operating debriefings were incompleted or not written in the register.

Despite these limitations we had been able to compare our results with those of others authors and make a discussion.

In 05 years, we collected 17 cases of laryngeal foreign body is $22 \%$ foreign bodies of the lower airways. In 2002, Ouoba [1] had found 34 cases in 10 years it gives 35.41\% foreign bodies of the lower airways. The frequency of laryngeal foreign body has changed very little in over a decade. Indeed, in 2007 Diop et al. [2] found in Dakar 65 cases in 16 years is $44.83 \%$ of foreign bodies of the lower respiratory tract.

The average age in our study was 61 months. Diop et al. [2] had regained an average age of 3 years. The highest average age in our series, figure an adult 35 years or most of our patients were aged between 6 months and 10 years. The sex ratio in our series was 1.4. Diop et al. [2] had recorded 2.42. This male is typically found in the literature, foreign bodies lower respiratory tract [1] [6]-[9]. Indeed, this is the little boy who pays the heaviest price in children and this is due to the quick temperament boys. In adults, the inhalation would be linked to poor dental status, swallowing disorders, psychiatric disorders or Parkinson's disease. The taking of drug-depressants of central nervous system and alcohol's consumption would also facilitate these accidents.

The entry deadline for our young patients was particularly long. Only 30\% were admitted within the first 24 hours after the accident. This long delay has also been found in several series [2] [10] [11]. The length of the intake period is explained both by the sub medicalization of our country and a certain degree of obscurantism families. A sudden onset of respiratory disorder is so often interpreted with an irrational approach, blamed on "bad spirits” even witchcraft. This observation is not peculiar to foreign bodies of the lower airways.

The laryngeal dyspnea was found in $47.05 \%$ of cases. It is most often associated with dysphonia in $58.8 \%$ of cases occurring in the background. Indeed, OUOBA [1] would have received $23.5 \%$ of cases in an array of respiratory distress.

The laryngeal foreign body most often results in a laryngeal dyspnea associated with dysphonia. This is explained by the obstruction of the laryngeal filiere already narrow in children, may require an extreme emergency treatment. The presence of a foreign body induced laryngeal edema which is added in minutes and complete 
blockage life-threatening. Diop et al. [2] were found in $83.07 \%$ of cases dyspnea and dysphonia in the remaining cases. The case dysphonia without dyspnea can be explained by the presence of a foreign body windowed allowing the ventilation airways.

The penetration syndrome was found in $23.5 \%$ of cases in our series. Diop et al. [2] observed a penetration syndrome in $90 \%$ of cases. Our low rate underestimates reality. Several reasons could explain this. Is a clinical failure linked to his name systematic research or lack of notification on file. Indeed whatever the foreign object still exists, even if it is more or less intense. It is obvious when witnesses are present. However it can be misunderstood especially among the young child alone or adults unable to speak clearly. In all cases there must be a "policeman" exam, strive to seek and to lift the emergency.

The foreign bodies were all organic and anorganic in our series. Most of the authors [1] [2] [7] [8] [12] notes a predominantly organic foreign bodies in the airways and this variably depending on eating habits.

The radiography has not been a capital diagnostic contribution or determinant in our study. The majority of the found foreign bodies, organic in nature, was radiotransparent. Furthermore, note that in a situation of great urgency, the realization of radiography is secondary [1] [2].

The treatment is based on endoscopy under general anesthesia to remove the foreign body. So overall there are few problems for the diagnosis of foreign body larynx, the treatment involves a series of difficulties already mentioned in part. Any foreign body airway or digestive which penetrated by natural means can be extracted through the same channels provided it has not migrated through the perforated wall of these pathways "said Chevalier Jackson [2].

The foreign bodies of the larynx do not escape this rule: they must be extracted endoscopically. Direct laryngoscopy Mac Intosh often associated with the larynx and tracheobronchial rigid tube was practiced for the removal of the foreign body in all patients in our series. The foreign bodies were subglottic in most cases or $70.6 \%$. The seat subglottic will explain that this is the narrowest portion of the laryngeal tube and inextensible and therefore be landlocked laryngeal foreign body.

The endoscopy was repeated in $35.3 \%$ of cases. This is explaining by two (02) main reasons. On the one hand, anesthetics reasons related to the precarious hematosis in children. Other parts, lack of suitable material that does not allow a proper grip. From where interest of the need to improve the technical plate. A tracheotomy was made in $11.7 \%$ of cases in our series, one before extraction to fight against the risk of acute asphyxia and intubation by tracheotomy orifice and one after extraction for laryngeal edema. In the series of Diop et al. [2], it was made in $44.38 \%$ of cases. Indeed, tracheotomy is required before a laryngeal paroxysmal dyspnea in a child to restore his life. The extraction will be performed secondarily. It can also be justified in postoperative when one fears a post-extraction laryngeal edema. However, decannulation must be early within 24 hours - 48 hours to preserve the mobility of the trachea in children.

Evolutionarily, the complications related to the inhalation of foreign bodies in children were significantly regressed as with advances in endoscopic instrumentation than the anesthetic approach. But the laryngeal foreign body is still encumbered with a heavy mortality in our context. One death was noted in $5.9 \%$ of cases in our series. Our results are similar to Diop et al. [2] who had returned 4.16\%. Note that the difficulties in the management of laryngeal foreign bodies and lower respiratory tract in general are numerous: the size and structure of the foreign body, the delay in admission, insufficient technical platform both in terms of endoscopy and anesthesia equipment and human resources.

\section{Conclusion}

The foreign bodies of the larynx are a serious disease that can be life-threatening. The explorer and therapeutic endoscopy under general anesthesia must be imposed ahead any suspicion of foreign body larynx. It will never be enough to insist on parent education, increased parental supervision of young children, a guarantee of effective evidence.

\section{References}

[1] Ouoba, K., Diara, C., Mo, D., Ouedraogo, I., Sanou, I. and Cisse, R. (2002) Les corps étrangers laryngotrachéo-bronchiques chez l'enfant au CHU de Ouagadougou. Médecine Tropicale, 62, 611-614.

[2] Diop, E.M., Tall, A., Diouf, R. and Ndiaye, I.C. (2000) Corps étrangers laryngés: prise en charge chez l'enfant au Sénégal. Archives de Pédiatrie, 7, 10-15. 
[3] INSD (2012) Enquête Démographique et de Santé et à Indicateurs Multiples (EDSBF-MICS IV) 2010. http://www.insd.bf/n/contenu/enquetes_recensements/enq_demo_sante/edsbf_mics_rapport_definitif.pdf

[4] DEP (Direction des Etudes et de la Planification)/Service de l’information sanitaire. Annuaire Statistique 2013. Ministère de la santé Burkina Faso. [En ligne]. 350 p. http://www.sante.gov.bf/index.php/publications-statistiques/file/409-annuaire-statistique-2013

[5] PNUD. Résumé Rapport sur le développement humain 2014. Programme des Nations Unies pour le développement [En ligne]. 30 p. http://www.undp.org/content/dam/undp/library/corporate/HDR/2014HDR/HDR-2014-Summary-French.pdf

[6] Kacouchia, N., et al. (2006) Corps étrangers des voies aéro-digestives chez l'enfant. Revue De Stomatologie Et De Chirurgie Maxillo-faciale, 13, 35-39.

[7] Kpemissi, E., Agbere, A., Kessi, K., Gnamey, K. and Assimadi, K. (1995) Corps étranger laryngo-trachéo-bronchique au Togo: Problèmes diagnostiques et thérapeutiques. Médecine Tropicale, 55, 4.

[8] Granry, J.C., Monrigal, J.P., Dubin, J., Preckel, M.P. and Tesson, B. (1999) Corps étrangers des voies aériennes. SFAR.

[9] Lescanne, E., Soin, C., Ployet, M.J., Lesage, V. and Mercier, C. (1997) Corps étrangers laryngo-trachéo-bronchiques. EMC ORL, 20-730-A-10, 32 p.

[10] Diouf Ba, M.S., Ndiaye, M., Deguenonvo, R., Thiam, A., Traore, M.M., Toure, S., et al. (2014) La mortalité chez les enfants porteurs de corps étrangers des voies respiratoires inférieures, expérience du service d’ORL de l'hôpital Aristide Le Dantec. Médecine d'Afrique Noire, 61, 368-372.

[11] Shubha, A.M. and Das, K. (2009) Tracheobronchial Foreign Bodies in Infants. International Journal of Pediatric Otorhinolaryngology, 73, 1385-1389.

[12] Ben Dridi, M.F., et al. (1985) Les corps étrangers des voies aériennes et des voies digestives supérieures: A propos de 123 observations. Tunisie Médicale, 63, 9-14. 